\title{
PEMODELAN SAMBUNGAN LAS PADA STRUKTUR BALOK KOLOM BAJA BERBASIS PROGRAM ELEMEN HINGGA
}

\author{
Gati Annisa Hayu ${ }^{1)}$ dan Machmud Budi Sulistyo ${ }^{2)}$ \\ 1) Program Studi Teknik Sipil, Universitas Pertamina, Jakarta, DKI Jakarta \\ 2) Jurusan Teknik Sipil, Universitas Jember, Jember, Jawa Timur \\ gati.hayu@universitaspertamina.ac.id
}

\begin{abstract}
In steel construction the selection of types and installation details of connection is an important thing that cannot be ignored. There are three types of steel connections, namely bolts, welds, and rivets. Welding connections have a good strength if conducted in proper quality control. In addition, these connections are also inexpensive and easy to implement. The focus of this study is the modelling of welding connections which can produce outputs that are close to the experimental results. The modelling is done by using finite element program. There are two models carried out; Model-1 uses tie constraint interaction type, meanwhile Model-2 uses merge and chamfer type. Results show that Model-2 is closer to the experimental result with an accuracy of $97.75 \%$ for its ultimate load. The deformation that occurred in Model-2 also resembles the experiment deformation. In terms of energy dissipation, the experimental result is $78,036.396 \mathrm{kN} . \mathrm{mm}$ while the result of Model-2 is $94,456.982$ kN.mm. Thus, the accuracy level of Model-2 is $82.62 \%$.
\end{abstract}

Keywords: displacement, dissipation energy, finite element, steel structure, welded joints

\begin{abstract}
ABSTRAK
Pada konstruksi baja pemilihan jenis dan detail pemasangan sambungan adalah faktor penting yang tidak dapat diabaikan. Terdapat tiga jenis sambungan baja, yaitu: baut, las, dan paku keling. Sambungan las akan menghasilkan kekuatan yang baik apabila dilakukan suatu kontrol kualitas yang tepat. Selain itu, sambungan las merupakan sambungan yang murah dan mudah diaplikasikan. Fokus dari penelitian ini adalah melakukan pemodelan sambungan las pada struktur balok kolom menggunakan program bantu elemen hingga yang mana hasilnya akan mendekati hasil dari suatu eksperimen yang sudah pernah dilakukan. Terdapat dua pemodelan yang dilakukan; Model-1 menggunakan interaksi jenis tie constraint interaction, sementara Model-2 menggunakan tipe merge and chamfer. Hasil penelitian menunjukan bahwa Model-2 lebih mendekati hasil eksperimen dengan tingkat akurasi beban ultimate sebesar 97.75\%. Bentuk deformasi yang terjadi pada model ini juga mendekati hasil eksperimen. Dalam hal energi disipasi, hasil eksperimen adalah sebesar 78,036.396 kN.mm sementara hasil untuk Model-2 adalah 94,456.982 kN.mm. Tingkat keakuratan hasil energi disipasi Model-2 mencapai $82.62 \%$.
\end{abstract}

Kata kunci: perpindahan, elemen hingga, energi disipasi, sambungan las, struktur baja 


\section{PENDAHULUAN}

Baja merupakan material yang banyak digunakan di bidang konstruksi. Selain sebagai tulangan, material baja juga digunakan pada bangunan gedung ataupun jembatan, seperti: jembatan penyeberangan orang, jembatan rangka baja, bangunan hotel, perkantoran, dan lain sebagainya (Sulistiyo, Hayu, \& Hidayah, 2019). Moment-resisting steel frame atau rangka baja pemikul momen didesain dengan asumsi bahwa struktur mampu menyediakan kekuatan, kekakuan, dan kemampuan disipasi energi yang cukup untuk menahan gempa yang parah (Calado, Castiglioni, \& Bernuzzi, 2000).

Struktur rangka baja pemikul momen dengan sambungan las dianggap sebagai salah satu rangka pemikul momen terbaik hingga terjadinya gempa Northidge pada tahun 1994. Akibat gempa yang besar, rangka baja pemikul momen mengalami kegagalan getas (brittle failure) pada bagian sambungan. (Aydin et al, 2015). Beberapa rangka pemikul momen baja terdeteksi mengalami kegagalan karena kerapuhan. Oleh karenanya, kajian teoritis dan eksperimen dilakukan dibeberapa negara seperti Amerika, Jepang, dan Eropa untuk mengamati perilaku siklik dari sambungan las (Calado \& Mele, 2000).
Sambungan antar komponen baja adalah hal penting yang tidak dapat diabaikan. Selain las, jenis sambungan pada konstruksi baja adalah baut dan paku keling. Sambungan las memiliki kekuatan yang baik apabila dilaksanakan dibawah kontrol mutu yang tepat. Selain itu, sambungan ini juga relatif murah. Sambungan baut mutu tinggi merupakan alternatif lain dalam penyambungan struktur baja. Ditinjau dari segi biaya, kinerja, dan tingkat kepraktisan, sambungan baut mutu tinggi mampu mengungguli paku keling (Dewobroto, 2016).

Pemilihan jenis sambungan dan detail pemasangan sambungan merupakan ciri khas dari konstruksi baja. Apapun jenis sambungannya diharapkan mampu menyediakan keandalan dan daktilitas yang tinggi pada struktur. Terdapat dua konsep untuk menjamin keandalan dan daktilitas tinggi pada struktur, yaitu memperkuat sambungan dan atau memperlemah balok terhadap kolom untuk menghindari kegagalan kolom (Sofias, Kalfas, \& Pachuomis, 2014).

Sebagai upaya untuk mengetahui kekuatan dan karakteristik dari berbagai jenis sambungan baja, maka dilakukan eksperimen di laboratorium. Pengujian di laboratorium dianggap efektif karena 
mampu memberikan hasil yang baik. Namun demikian, diperlukan data pengujian yang banyak untuk mendapatkan hasil yang akurat. Hal ini tentu saja membutuhkan tenaga, waktu, dan biaya yang tidak sedikit (Subchan, Hayu, \& Hidayah, 2019).

Seiring dengan perkembangan teknologi komputasi, seperti finite element method, saat ini memungkinkan untuk melakukan simulasi yang kompleks dengan banyak parameter dengan menggunakan program elemen hingga (Mohamadi-shooreh \& Mofid, 2013). Selain itu, kesulitan pelaksanaan eskperimen yang berfokus pada sambungan menjadikan penggunaan program elemen hingga non-linier untuk analisis sambungan dan penentuan kurva momen-rotasi menjadi lumrah dilakukan. (Abdollahzadeh \& Shabanian, 2013). Pemodelan elemen hingga dirasa mampu menghemat waktu dan biaya serta menampilkan visual yang lebih detail. Kemampuannya dalam menampilkan perilaku yang sebenarnya pada sambungan menjadikannya sebuah alternatif absah sebagai standard pengujian dan sumber pengetahuan yang mahal untuk perilaku sambungan (Sabatka et al, 2014). Diperlukan suatu pendekatan algoritma yang tepat untuk mendapatkan hasil yang akurat.

Pada penelitian ini dilakukan pemodelan sambungan las pada balokkolom baja IWF dengan menggunakan program elemen hingga. Dua pemodelan dilakukan untuk mengetahui jenis pemodelan yang dapat menghasilkan keluaran yang mendekati hasil eskperimen. Parameter yang ditinjau meliputi bentuk kurva histeresis, kontur tegangan dan deformasi, serta energi disipasi.

\section{KAJIAN PUSTAKA}

Data material, konfigurasi sambungan, dan juga pembebanan pada penelitian ini disesuaikan dengan penelitian yang telah dilakukan oleh Yang dan Kim pada tahun 2007 (Yang \& Kim, 2007). Salah satu eksperimen yang dilakukan adalah las sempurna (fully welded).

Komponen yang dimodelkan meliputi balok baja IWF dengan bentang $120 \mathrm{~cm}$, kolom baja IWF degan tinggi 220 $\mathrm{cm}$, dan sambungan las. Mutu baja yang digunakan adalah SS400. Data material dan konfigurasi sambungan las baja yang digunakan ditampilkan pada Tabel 1 dan Gambar 1. 
Tabel 1. Data Material

\begin{tabular}{cccc}
\hline \multicolumn{4}{c}{ Kolom } \\
H $125 \times 125 \times 6.5 \times 9$ \\
fy flange & $347 \mathrm{MPa} \quad$ fy web & $333 \mathrm{MPa}$ \\
$\varepsilon$ flange & $466 \mathrm{Mpa} \quad$ fu web & $461 \mathrm{MPa}$ \\
\multicolumn{4}{c}{ Balok } \\
\multicolumn{4}{c}{ H $250 \times 125 \times 6 \times 9$} \\
fy flange & $328 \mathrm{MPa} \quad$ fy web & $322 \mathrm{MPa}$ \\
fu flange & $447 \mathrm{Mpa} \quad$ fu web & $423 \mathrm{MPa}$ \\
$\varepsilon$ flange & $31.25 \% \quad \varepsilon$ web & $32.5 \%$ \\
Ukuran Las \\
flange & $9 \mathrm{~mm} \quad$ web & $6 \mathrm{~mm}$ \\
Sudut las & $45^{\circ}$ & \\
\hline Sumber: Yang \& Kim, 2007
\end{tabular}

Sumber: Yang \& Kim, 2007

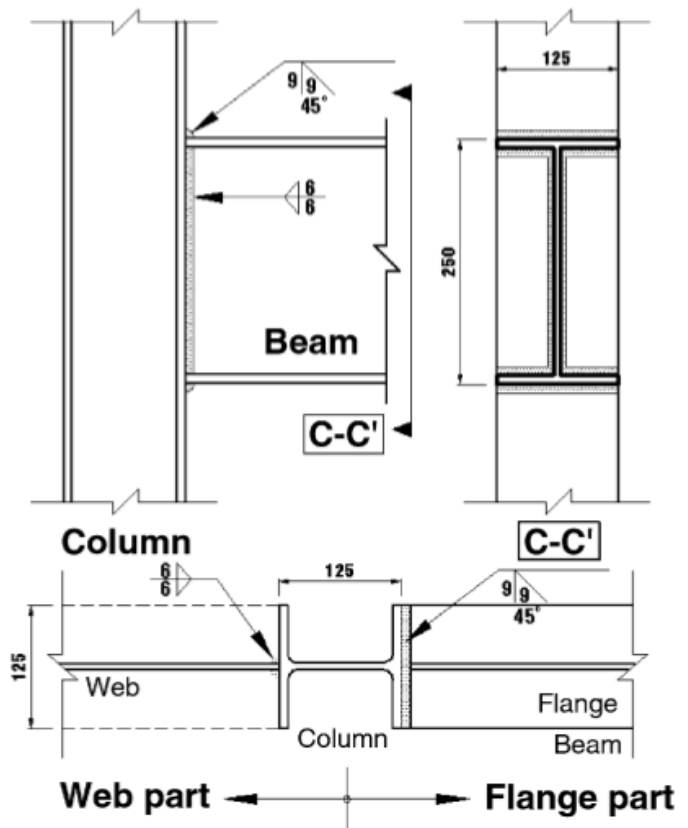

Gambar 1. Konfigurasi Sambungan Las (Sumber: Yang \& Kim, 2007)

\section{METODE PENELITIAN}

Metode penelitian diawali dengan membuat pemodelan sambungan las pada balok kolom baja IWF menggunakan program bantu elemen hingga. Terdapat dua jenis pemodelan yang dilakukan, yaitu Model 1 dan Model 2 yang dibedakan berdasarkan asumsi algoritma interaksinya.
Hubungan tegangan dan regangan plastisitas baja diklasifikasikan menjadi perfectly plastic, elasto-plastic strain hardening, dan elasto-plastic strain softening (Ray, 2015). Pada penelitian ini perilaku balok kolom baja dimodelkan dengan perfectly plastic dimana setelah melewati batas elastisnya, baja tidak mengalami strain hardening. Dengan demikian hanya diperlukan data fy dan nilai regangan plastis sebesar 0 .

Tahap penentuan interaksi antar komponen merupakan tahap yang penting dalam pemodelan elemen hingga. Pemilihan interaksi yang tepat akan menghasilkan output yang akurat. Telah disebutkan sebelumnya bahwa jenis las yang digunakan adalah las sempurna yang menjamin tidak ada slip diantara balok dan kolom. Untuk menghasilkan perilaku las sempurna maka Model 1 menggunakan interaksi tie constraint. Hal ini serupa dengan pemodelan yang dilakukan oleh Atei dkk (Ataei, Bradford, \& Liu, 2017), Li dkk (Li, Uy, \& Wang, 2019), Sabbagh dkk (Sabbagh et al, 2013) dan Xu dkk (Xu et al, 2017) yang menggunakan interaksi jenis tie constraint untuk menghasilkan perilaku las sempurna. Sementara itu Model 2 menggunakan merge pada seluruh komponen penyusun. 


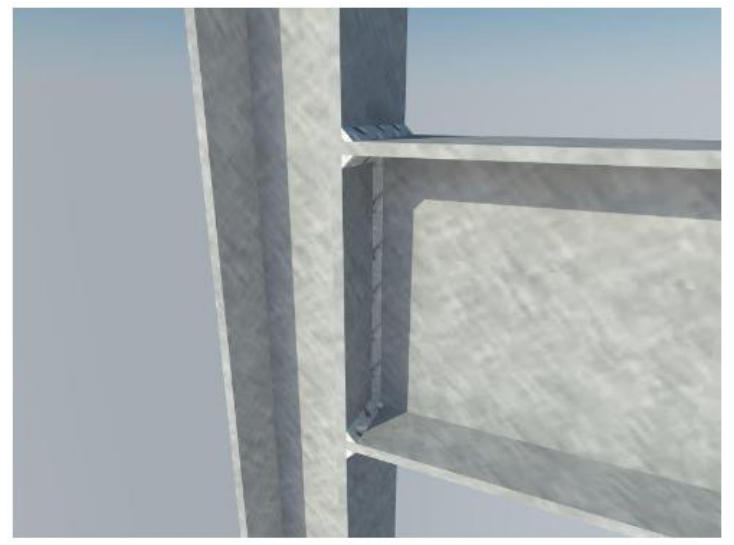

Gambar 2. Pemodelan Balok-Kolom dengan Elemen Hingga

Pada Model 1 balok dan kolom tidak dilakukan merge sehingga perintah constraint dapat dilakukan. Bagian sayap kolom perlu dipartisi sedemikian rupa sehingga dapat sesuai dengan permukaan balok IWF yang melekat padanya. Sementara itu seluruh komponen pada Model 2 dilakukan merge. Sambungan las antar komponen diwakili dengan perintah chamfer.

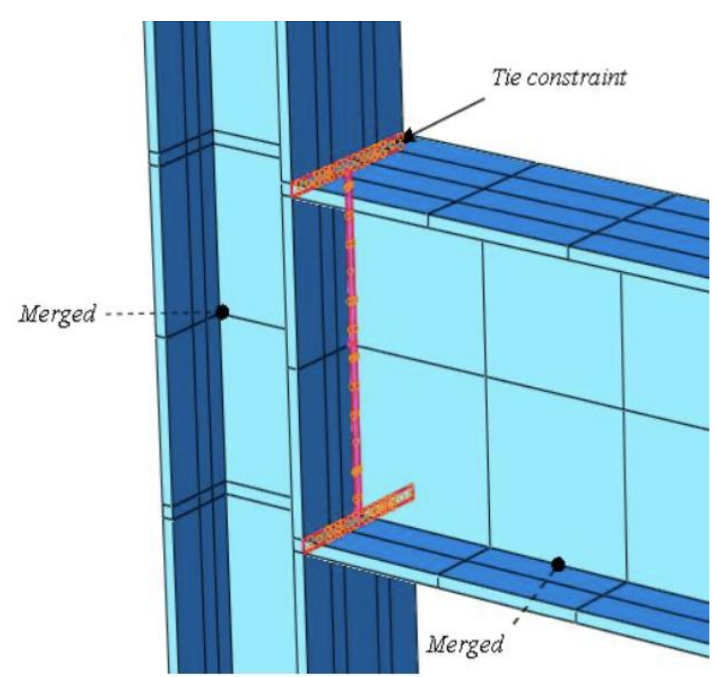

Gambar 3. Interaksi Model 1
Ukuran las $9 \mathrm{~mm}$ diaplikasikan pada pertemuan sayap kolom dengan sayap balok. Ukuran las $6 \mathrm{~mm}$ diaplikasikan diantara sayap kolom dengan badan balok. Komponen balok dan kolom digabung menjadi satu untuk selanjutnya diberi ukuran las sesuai data eksperimen.

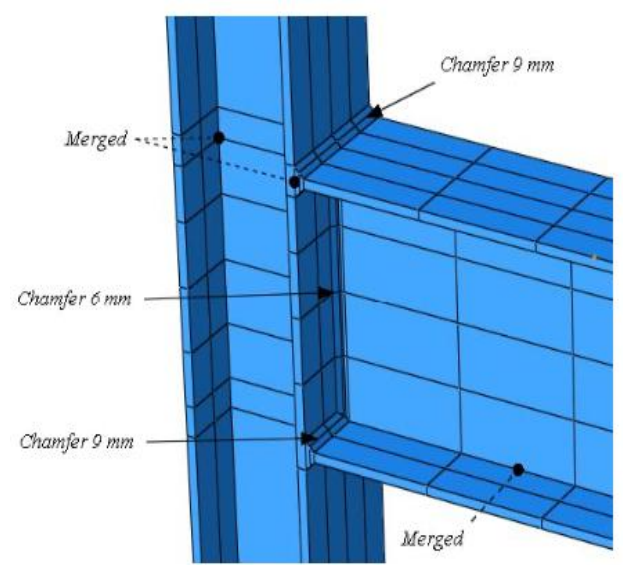

Gambar 4. Interaksi Model 2

Pembebanan yang diberikan merupakan pembebanan siklik vertikal yang diaplikasikan pada jarak 1000 mm dari as kolom. Input beban menggunakan kenaikan displacement dimulai dari nilai 0 $\mathrm{mm}, \pm 3 \mathrm{~mm}$ hingga $\pm 100 \mathrm{~mm}$, dan berakhir Kembali ke $0 \mathrm{~mm}$. Total steps untuk mewakili pemberian beban adalah 73 steps. Pada kedua ujung kolom dipilih boundary condition terjepit sempurna (encastre) dimana kedua ujung kolom ini dianggap mampu menahan rotasi maupun translasi. Pemodelan kedua ujung kolom serupa dengan pemodelan yang dilakukan oleh Li et al. pada tahun 2019 (Li, Uy, \& Wang, 2019). 


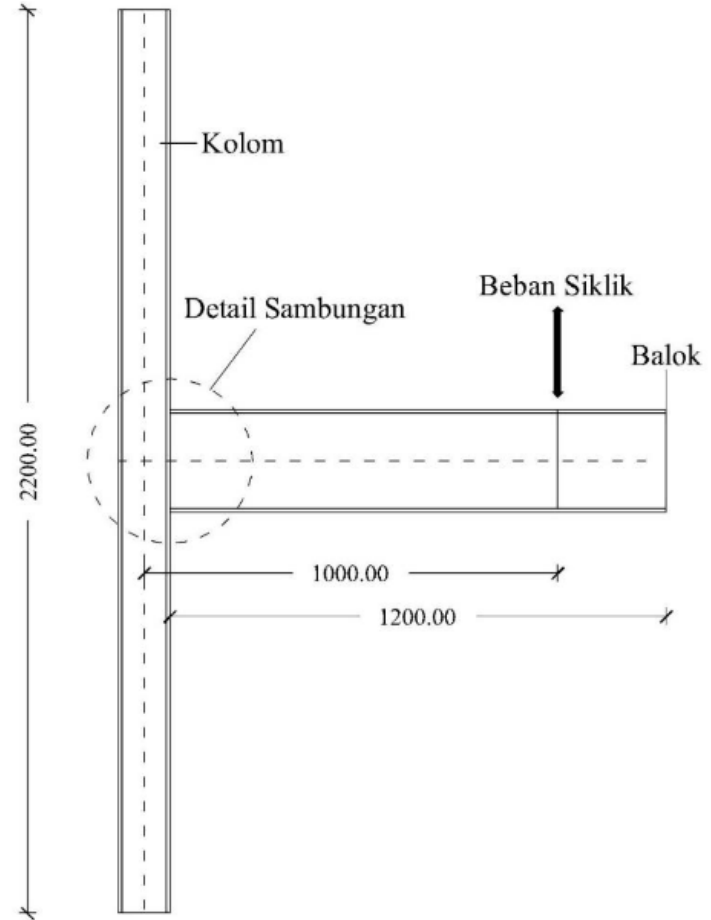

Gambar 5. Ilustrasi Pembebanan Siklik (Sumber: Sulistiyo, Hayu, \& Entin, 2019)

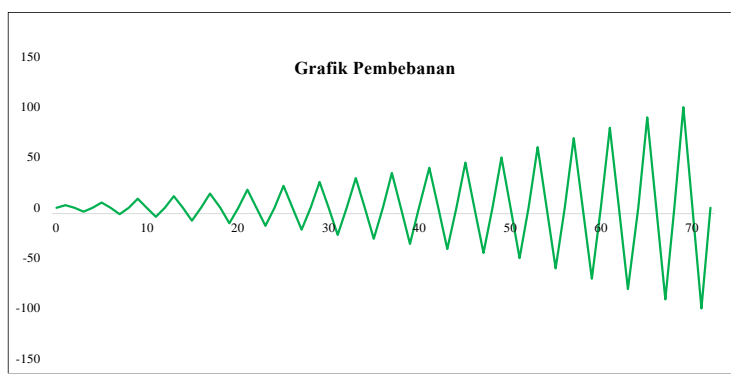

Gambar 6. Grafik Input Pembebanan Siklik

\section{HASIL DAN PEMBAHASAN}

\subsection{Kurva Histeresis}

Hubungan antara kapasitas beban dan perpindahan disajikan dalam kurva histeresis pada Gambar 7 dan 8. Kapasitas beban adalah beban yang mampu dipikul oleh balok selama diberi beban siklik. Beban berbanding lurus dengan nilai perpindahan, sehingga semakin besar nilai perpindahan yang diberikan maka semakin besar pula gaya yang dipikul oleh balok.
Gambar 7 dan 8 menampilkan perbandingan kurva histeresis antara pemodelan elemen hingga dengan hasil eksperimen. Terlihat bahwa antara hasil pemodelan (biru) dengan eksperimen (oranye) tidak jauh berbeda. Namun demikian bentuk kurva sedikit berbeda pada bagian akhir.

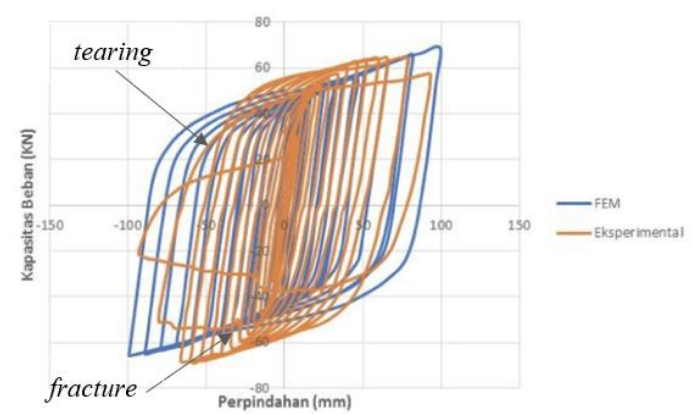

Gambar 7. Perbandingan Kurva Histeresis Model 1 dan Eksperimen

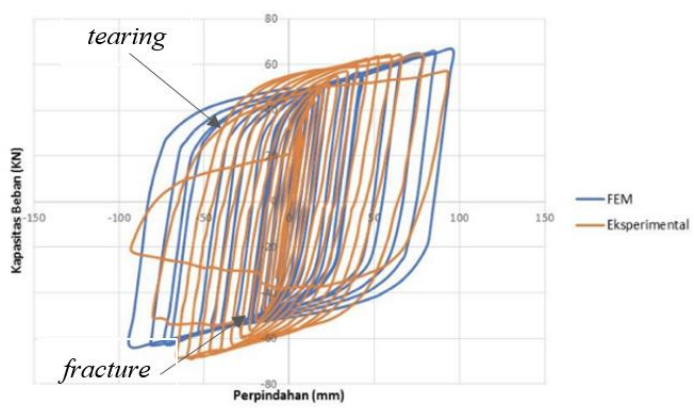

Gambar 8. Perbandingan Kurva Histeresis Model 2 dan Eksperimen

Model 1 mengalami leleh pertama dengan nilai beban sebesar $\pm 43.85 \mathrm{KN}$ dan deformasi sebesar $\pm 10.38 \mathrm{~mm}$. Sementara itu, Model 2 mengalami leleh pertama dengan nilai beban sebesar $\pm 42.79 \mathrm{kN}$ dan nilai deformasi sebesar $\pm 8.62 \mathrm{~mm}$. 
Beban ultimit yang dihasilkan oleh Model 1 dan Model 2 masing-masing adalah $68.52 \mathrm{kN}$ dan $66.43 \mathrm{kN}$. Sementara hasil eksperimen memiliki kapasitas beban ultimit sebesar $66.6 \mathrm{kN}$. Dengan demikin nilai keakuratan Model 1 dan Model 2 terhadap hasil eksperimen adalah sebesar $97.21 \%$ dan $99.75 \%$.

$$
X=100 \%-\frac{(X F-X E)}{X F} \times 100 \% \ldots \ldots \ldots . . .
$$

Dimana $\mathrm{X}$ adalah nilai keakuratan pemodelan, $\mathrm{X}_{\mathrm{F}}$ hasil pemodelan elemen hingga, dan $\mathrm{X}_{\mathrm{E}}$ adalah hasil eksperimen laboratorium.

Model 2 mempunyai kekuatan leleh yang lebih kecil dibandingkan dengan Model 1. Perbedaan nilai beban diantara keduanya adalah $2.42 \%$. Hal yang sama juga ditunjukkan oleh nilai beban ultimitnya, Model 2 menghasilkan nilai beban yang lebih kecil sebesar 3.1\% dibandingkan Model 1.

Ditinjau dari displacement, hasil eksperimen memiliki nilai sebesar 59.5 $\mathrm{mm}$ ketika mencapai beban ultimate sebesar $66.6 \mathrm{kN}$. Model 1 memiliki perpindahan sebesar $58.3 \mathrm{~mm}$ dengan beban yang bekerja sebesar $60 \mathrm{kN}$. Sementara Model 2 memiliki perpindahan sebesar $59.3 \mathrm{~mm}$ dengan beban yang bekerja sebesar $60.37 \mathrm{~mm}$. Dapat dilihat bahwa dengan nilai perpindahan yang hampir sama, pemodelan elemen hingga menghasilkan kapasitas beban yang lebih kecil. Berdasarkan beban leleh, displacement, dan beban ultimitnya, maka terlihat bahwa Model 2 menghasilkan keluaran yang lebih mendekati hasil eksperimen.

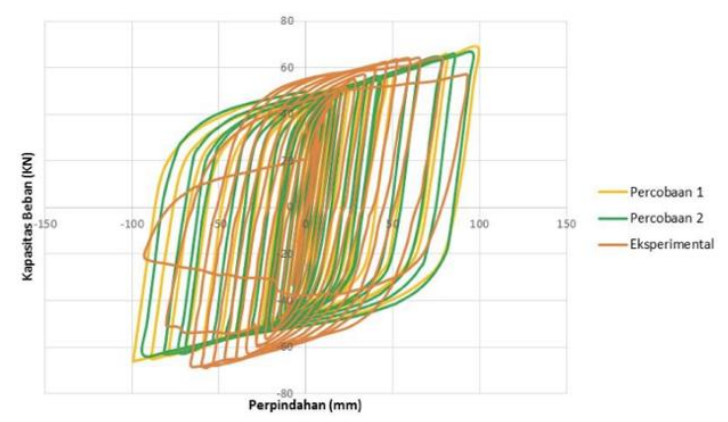

\section{Gambar 9. Perbandingan Kurva Histeresis Seluruh Model dan Eksperimen}

Grafik sedikit berbeda pada tahap akhir pembebanan, ini dikarenakan input tegangan pada program elemen hingga tidak melampirkan tegangan ultimit karena baja terus berdeformasi dalam kondisi perfetly plastic. Oleh karenanya hasil pemodelan tidak menunjukkan perilaku fatik. Hasil analisis yang sama juga ditunjukkan pada penelitian yang dilakukan oleh Abdollahzadeh dan Shabanian (Abdollahzadeh \& Shabanian, 2013). Pada algoritma interaksi sambungan las juga tidak memasukkan mutu las yang digunakan, ini adalah salah satu penyebab mengapa terdapat perbedaan antara hasil pemodelan dan eksperimen. 


\subsection{Kontur Tegangan dan Deformasi}

Gambar 10 dan 11 merupakan deformasi yang terjadi pada sambungan las hasil pemodelan elemen hingga dan eksperimen. Kondisi plastis pemodelan las hampir menyamai hasil eksperimen laboratorium.

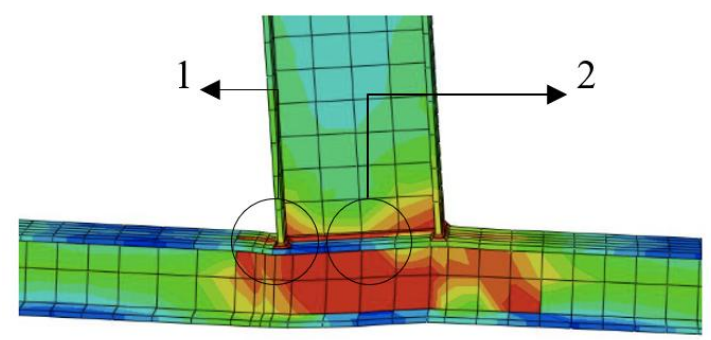

Gambar 10. Deformasi Pemodelan Elemen Hingga

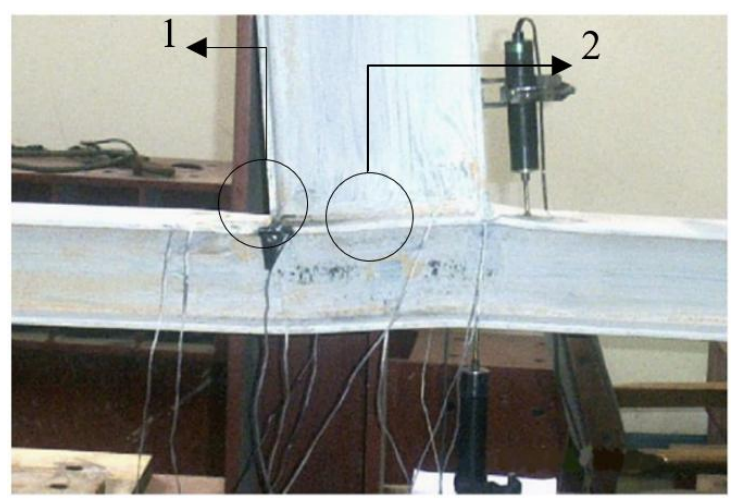

Gambar 11. Deformasi Hasil Eksperimen

Kontur warna merah menunjukkan nilai tegangan yang lebih besar dibandingkan warna lainnya. Dari hasil pemodelan diketahui bahwa pada area 1 terdapat kontur warna merah pada bagian flange kolom yang mengalami tegangan terbesar, yakni 315.3 MPa. Sementara dari hasil percobaan diketahui bahwa pada area yang sama telah terjadi sobek. Hasil eksperimental juga menunjukkan bahwa gradual tearing terjadi pada flange kolom dan web balok pada area dekat sambungan las dengan flange kolom (area 2).

\subsection{Energi Disipasi}

Selain membandingkan kapasitas beban yang mampu diterima balok sebagai ukuran keakuratan pemodelan, penelitian ini juga membandingkan energi disipasi yang dihasilkan. Hubungan antara gaya dan perpindahan akibat pemberian beban siklik menghasilkan suatu kurva yang disebut dengan hysteresin loop. Luasan dari hysteresis loop ini menunjukkan besarnya energi yang didipasi oleh struktur (Ambarita, Teruna, \& Karolina, 2014).

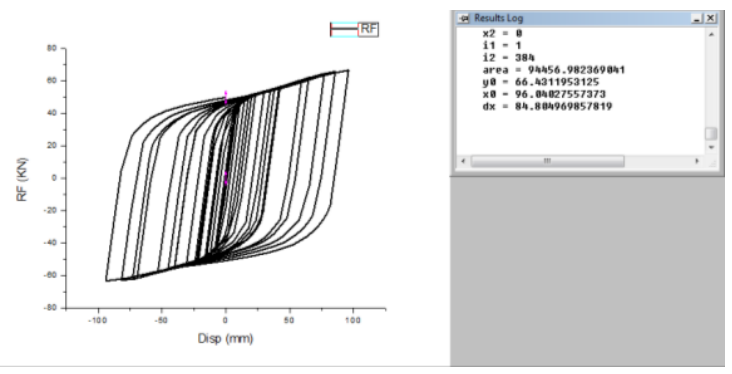

Gambar 12. Hysteretic Loop Pemodelan Elemen Hingga

Hasil eksperimen menunjukkan bahwa luasan hysteresis loop atau energi disipasi adalah sebesar 78,036.396 kN.mm atau sebesar $78.036 \mathrm{~kJ}$ sementara itu hasil pemodelan elemen hingga sebesar 94,456.982 kN.mm atau sebesar 94.457 kJ. Dengan demikian keakuratan model adalah sebesar $82.62 \%$. 


\section{SIMPULAN DAN SARAN}

\subsection{Simpulan}

Beberapa kesimpulan yang dapat diambil dari penelitian ini adalah:

1. Ditinjau dari segi kekuatan ultimit yang dihasilkan, Model 2 menghasilkan keakuratan lebih baik dibandingkan Model 1, yakni sebesar $99.75 \%$.

2. Model 2 dengan asumsi merged pada seluruh komponen baja dan chamfer menghasilkan output yang mendekati eksperimen.

3. Deformasi yang terjadi pada pemodelan mendekati deformasi hasil eksperimen.

4. Ditinjau dari energi disipasi yang dihasilkan, Model 2 memiliki tingkat keakuratan sebesar $82.62 \%$.

\subsection{Saran}

Beberapa saran yang dapat diambil dari penelitian ini adalah:

1. Memodelkan perilaku plastis material baja dengan lebih tepat.

2. Memodelkan interaksi baja dengan input mutu sambungan las yang digunakan.

3. Menganalisis momen-rotasi pada sambungan las balok kolom.

\section{DAFTAR PUSTAKA}

Abdollahzadeh, A., Shabanian, S. M. (2013). Analytical and Experimental Studies on Behavior of Beam to Column Connections with Flange Plate under Monotonic Loading. Iranica Journal of Energy \& Environmental, 4, 2018-211.

Ambarita, J., Teruna, D. R., Karolina, R. (2014). Pendekatan Model Hysteretic Steel Damper Berdasarkan Hasil Eksperimental. Jurnal Hasil Riset: JP Civil Engineering.

Ataei, A., Bradford, M. A., Liu, X. (2017). Computational Modelling of the Moment-rotation Relationship for Deconstrucable Flush End Plat Beam-to-column Composite Joints. Journal oc Constructional Steel Research, 129, 75-92.

Aydin, A. C., Kilic, M., Maali, M., Sagiroglu, M. (2015). An Experimental Study on the Moment Rotation of Bolted Beam-Column Connections. Proceeding of The Third International Conference on Advances in Civil, Structural and Environmental Engineering, 141146.

Calado, L., Castiglioni, C. A., Bernuzzi, C. (2000). Seismic Behaviour of Welded Beam-to-column Joints: Experimental and Numerical Analysis. Researchgate.

Calado, L., Mele, E. (2000). Experimental Behavior of Steel beam-to-column Joints: Fully Welded vs Bolted Connections. 12WCEE2000.

Dewobroto, W. (2016). Struktur Baja: Perilaku, Analisis \& Desain - AISC 2010 Edisi ke-2. Penerbit: Jurusan Teknik Sipil UPH.

Li, D., Uy, B., Wang, J. (2019). Behaviour and Design of High-Strength Steel Beam-to-column Joints. Steel and 
Composite Structures, 31 (3): 303317.

Mohamadi-shooreh, M. R., Mofid, M. (2013). Prediction of the Yielding Moment of Flush Endplate Connections Using Finite Element Modeling. Scientia iranica, 20(2), 270-277.

Ray, R. (2015). Elasto-plastic Analysis of Plate Using Abaqus, Rourkela: Departement of Civil Engineering National Institut of Technology Rourkela.

Sabbagh, A. B., Chan, T. M., Mottram, J. T. (2013). Detailing of I-beam-to CHS Column Joints with External Diagram Plates for Seismic Actions, J. Construction Steel Res, 88, 21-33.

Sabatka, L., Wald, F., Kabelac, J., Godrich, L., \& Navratil, J. (2014). Component Based Finite Element Model of Structural Connections. Proceeding of $12^{\text {th }}$ International Conference on Steel, Space abd Composite Structures.

Sofias, C., Kalfas, C., Pachuomis, D. (2014). Experimental and FEM Analysis of Reduced Beam Section Moment Endplate Connections under Cyclic Loading. Engineering Structures, 59, 320-329.

Subchan, B., Hayu, G. A., Hidayah, E. (2019). Analisis Perilaku Efek Retrofit Kolom Beton Berkomposisi Steel Fiber (Engineered Cementitious Composite / ECC) akibat Beban Aksial dengan Menggunakan Software Berbasis Finite Element Analysis. Rekayasa Sipil, 13(3), 207-215.

Sulistiyo, M.B., Hayu, G.A., Hidayah, E. (2019). Analisis Sambungan baut Balok Kolom Rangka Baja Struktural dengan Profil IWF Menggunakan Program Bantu
Elemen Hingga. Rekayasa Sipil, 13(3), 199-206.

Xu, F., Chen, J., Chan, T.M. (2017). Numerical Analysis and Punching Shear Fracture Based Design of Longitudinal Plate to Concrete-filled CHS Connections. Construction Building Material, 156, 91-106.

Yang, C., Kim, Y. (2007). Cyclic Behavior of Bolted and Welded Beam-toColumn Joints. International Journal of Mechanical Sciences, 49, 635649. 